\title{
Amazonas sin sombrero: el ego fálico (pos)colonial y la objetivación de la mujer en relatos de viajeros europeos en el Chile decimonónico ${ }^{1}$
}

\author{
Amazons without a hat: the phallic (post)colonial ego and the \\ objectification of women in European travelogs in Chile (19th \\ century)
}

\author{
Eduardo Gallegos \\ Universidad de la Frontera \\ eduardo.gallegos@ufrontera.cl
}

\section{Resumen}

El trabajo estudia la forma en que se (re)produce una mirada erótica que se define aquí como una continuidad del ego fálico colonial, pero ahora en la situación poscolonial, a través del análisis de un corpus de catorce relatos de viajeros europeos en el Chile decimonónico. Se arguye que esta mirada erótica es parte de la mirada imperial que se proyecta hacia la mujer, lo que permite dar cuenta de dos grandes dinámicas en tensión como resultado del análisis. En la primera tensión la mujer aparece como objeto de entretención y servicio, objetivada la vez por la emocionalidad y la racionalidad como rasgos arbitrariamente exigidos. En la segunda tensión, la mujer aparece como objeto de intercambio, articulada de manera compleja por las categorías de raza y clase.

Palabras clave: ego fálico, mirada imperial, objetivación, relato de viaje.

\begin{abstract}
This paper aims to study how an erotic gaze is produced in the postcolonial situation. Thirteen travel logs are analyzes corresponding all to european travelers in chiel at 19th century. The erotic gaze is understood as continuity of the phallic colonial ego, and it is argued that is part of the imperial gaze that is projected towards women. This analysis enables to identify two dynamics in tension: first, the women appear as an object of entertainment and service and stressed at the same time
\end{abstract}

1 Proyecto DI19-0036. Financiado por la Vicerrectoría de Investigación y Postgrado de la Universidad de La Frontera. "De los relatos de viajes a los relatos periodísticos: Imaginarios sobre lo mapuche en relatos de viajeros europeos del siglo XIX y su vinculación con la prensa chilena del siglo XIX y principios del siglo XX". 
by emotionality and rationality as arbitrarily demanded features. Second, women appear as an object of exchange and stressed in a complex way by the categories of race and class.

Keywords: phallic ego, imperial gaze, objectification, travelog

Recibido: 01/06/2020

Aceptado: 09/09/2021

\section{E1 Ego fálico (pos)colonial: exotización, erotismo y género en los relatos de viajeros europeos en Chile}

La idea del ego fálico la retomamos desde Dussel (50) a propósito de la actitud de los colonizadores españoles del s. XV y XVI frente a las mujeres indígenas. Según Dussel la relación que se establece entre conquistadores (españoles) y conquistados (indígenas) es una relación de violencia y dominación donde el otro debe ser doblegado. A partir de ahí comienza un proceso ya no de conquista sino que de "colonización del mundo de la vida", donde: "La violencia erótica vino simplemente a mostrar la "colonización” del mundo de la vida indígena." (Dussel 50)

También en un sentido colonial, la idea de "visión pornográfica de los eventos" (Townsend 660) se ha referido a la dinámica política subalterna de la situación colonial en cuanto los indígenas —más allá de las violencias explícitas acometidas contra ellos - fueron considerados entusiastas y pasivos aduladores del proyecto colonial por los propios hombres blancos.

Se considera en este trabajo la continuidad de estas formas de violencia simbólica en la situación poscolonial entendida aquí como la continuidad de las formas coloniales una vez logradas las independencias nacionales: "Obsérvese que el "pos" no indica un momento en el que ya se ha superado el colonialismo sino la toma de conciencia de las continuidades y legados coloniales aun siglos posteriores a las independencias políticas" (Rabasa 218). ${ }^{2}$

El discurso poscolonial está relacionado con la producción de conocimiento por parte de agentes de las potencias imperiales: escritores viajeros, misioneros, mercaderes, etnógrafos, científicos, etc. (Chrisman 1858). De ahí la importancia

2 Se considera aquí entonces lo poscolonial como el "colonialismo post-colonial". Esta posición en torno a lo poscolonial no desconoce toda la literatura que discute el concepto junto con sus limitaciones y posibilidades de definición. Para el lector interesado en la (re)definición de lo poscolonial: Spivak (1860); Cooper (33); Thompson (xvi). Para fines de este trabajo es particularmente interesante la vinculación que realiza Claire Lindsay (31) entre escritura de viajes y los estudios poscoloniales. 
de los relatos de viajes en la configuración de esta mirada poscolonial e imperial, según se definirá más adelante.

Se arguye aquí que la temática parece pertinente de ser abordada a propósito de la vinculación entre los estudios de género y el análisis de los relatos de viajes. Al respecto, parece relevante el hecho de que la entrada "sexo/sexualidad" aparece en el reciente diccionario Keywords for Travel Writing Studies a propósito del atractivo que generó - y aún genera - para muchos la posibilidad de viajar, en cuanto oportunidad de evadir las expectativas morales, sexuales y culturales del lugar de origen (Scott 223). Del mismo modo, el diccionario citado recoge también la noción de género arguyendo que en el viaje surge la posibilidad de que las nociones de género se vuelvan móviles y cambiantes, lo que da la posibilidad de tensionar las nociones de masculinidad y feminidad (Bird 99).

El trabajo ya clásico de Mary Louise Pratt, Ojos imperiales, señala que desde fines del s.XVIII y principios del s.XIX se articula una tensión en los relatos de viajes entre la escritura de espectáculo popular, orientada a la entretención, y la enciclopedista culta, orientada a la información, (cfr. Gallegos y Otazo 840). En esta tensión el exotismo y la erotización jugaban un rol importante: "La relación lector-texto se codifica en los mismos términos masculinistas y erotizados que codificaron la relación del viajero europeo con los países exóticos que visitaba" (172). Del mismo modo, la mirada imperial se configura desde el "yo imperial", descrito en la frase "soy monarca de todo lo que veo" (Pratt 61).

Así, Spurr (267) apunta a la erotización como uno de los tropos retóricos preponderantes referidos a la representación imperial donde aparece una promesa sexual, peligros sexuales, una visión erótica del paisaje, el desvelamiento del cuerpo femenino, entre otras formas de erotización.

Las ideas teóricas hasta aquí expuestas son visualizadas junto a otras a las que se referirá cuando sea pertinente en un total de catorce relatos de viajeros europeos donde se contabilizan cuatro alemanes, cuatro ingleses, tres franceses, un belga, un sueco y un estadounidense. Se trata de observar en estos relatos la forma en que se representa la mujer criolla e indígena desde la mirada imperial-poscolonial. Se podrá encontrar en la mayoría de las obras consultadas referencias bibliográficas que permiten comprender el objetivo de cada uno de los catorce viajeros que conforman el corpus. ${ }^{3} \mathrm{El}$ periodo de los viajes comprende todo el siglo XIX desde la postindependencia (de 1825 es el texto más antiguo del que disponemos) hasta

3 Otras referencias a los viajes y viajeros que aquí se citan pueden encontrarse en "Viajes relativos a Chile" (tomo I y II), Guillermo Feliú Cruz; "Diccionario histórico, biográfico y bibliográfico de Chile", Vírgilio Figueroa y en "A Bibliography of South America", T.H. O’Halloran; entre otros. 
fines de siglo, siendo el viaje del geólogo sueco Otto Nordenskjöld el más reciente realizado en la patagonia chileno-argentina entre 1895-1896, pero publicado en la revista francesa Le Tour du Monde en 1902. Si bien la naturaleza de cada uno de estos viajes es disímil y se encuentran viajes relativos a experiencias científicas, comerciales, de prospección minera, o simplemente por el afán de conocer, esto se relaciona con la naturaleza heterogénea e híbrida del relato de viajes. En este sentido y respecto a las salvaguardas metodológicas requeridas para el trabajo con este tipo de textos desde las humanidades se siguen aquí los lineamientos planteados por Junqueira (47) y Scatena (67).

La relevancia del análisis propuesto recae en la posibilidad de rastrear en los textos del corpus no tan solo la representación de la mujer, sino que además de esto, considerar la imposición de prácticas, rituales e instituciones que favorecieron determinadas formas de pensar los roles de la mujer y sus implicancias actuales.

\section{La mujer como objeto de entretención y servicio: entre la emocionalidad y la racionalidad}

En el marco de las relaciones subalternas que se producen entre los centros imperiales y las antiguas colonias españolas de las que se trata de obtener sendos réditos económicos, las mujeres aparecen con una doble dimensión de subalternidad. La primera, asociada a que son mujeres y, por lo tanto, inferiores al hombre según el sentir de la época. La segunda, se trata de sujetos que viven en la periferia de las metrópolis y del mundo civilizado. Estas mujeres entonces, deben servir a la entretención e integración de los extranjeros.

Al respecto, Samuel Haigh describe la presencia de una comitiva de oficiales ingleses y señala que: “. . .fueron siempre tratados con gran hospitalidad y atención por las hermosas chilenas, en una serie de fiestas, pues cada vez que se reunía algún grupo se organizaban tertulias (90)". En otra parte el inglés señala:

Las niñas son muy bonitas con su cutis mucho mejor que todas las que he visto en Sudamérica; algunas tienen ojos azules y pelo obscuro; tienen muy buen humor y son muy amables. Sus entretenciones no difieren mucho de las de la República de Buenos Aires, pero apenas si se han acercado tanto a las costumbres europeas. Tocan y bailan a la guitarra, muchas al piano, y son muy vivas en su trato y conversación. (36)

La mujer aparece como entretención, como bufón de una corte varonil. El rol social de la mujer queda asociado y restringido entonces al buen genio, al trato cor- 
dial y a la conversación sencilla y complaciente, con una emocionalidad al servicio del hombre. La función de la mujer en la narrativa de viajes responde en parte, y en este caso, a una tradición sentimental donde lo político se manifiesta en las esferas de lo doméstico, y como se verá más adelante, también en lo erótico. ${ }^{4}$

Algo similar ocurre en el texto del francés Max Radiguet, un amante de la bohemia de Valparaíso, quien se detendrá en extensos pasajes de su relato a dar cuenta de los salones de baile donde las mujeres están en el centro de la narrativa como fuente/objeto de entretención y espectáculo. Al respecto, y después de una primera descripción de las mujeres al llegar al centro de la ciudad el francés señala: “. . .pero ¿conviene dejarse llevar de esa primera impresión y no vale la pena seguir a las chilenas a sus salones, su verdadero teatro? Esto también equivaldrá a conocer la vida de Valparaíso bajo su aspecto más seductor" (Radiguet 227). La relación sobre las mujeres que Radiguet va construyendo se asocia a las conversaciones con las mujeres en los salones (229) el baile de la zamacueca (234); los viajes a la playa (235-6), entre otros eventos sociales de orden recreativo, donde las mujeres son "actrices de un teatro" según la cita arriba expuesta.

La tensión aparece en cuanto al mismo tiempo que se valoran estas dimensiones del genio, la entretención, y la emocionalidad de la mujer, algunos relatos estudiados apelan también al carácter más racional y menos sentimental que las chilenas supuestamente poseen. Citamos nuevamente a Samuel Haigh al respecto:

No sé como no se encuentran [las chilenas] en un estado mental aún más sano que las niñas de esos países, donde tienen la imaginación siempre agitada por la "última novela" y que por lo tanto, tienen una buena dosis de sentimentalismo del cual carecen las que tienen modos más avanzados de pensar en Chile (36).

Así, Haigh modela y piensa a la mujer desde los espacios que son más convenientes para él. Desde su locus de enunciación imperial-patriarcal tiene la potestad de vetar y esperar ciertos comportamientos, aunque estos sean en ocasiones contradictorios, puesto que la amabilidad, el humor y la candidez en el trato — como forma de valoración positiva-, aparece después en una dimensión contraria al vilipendiar el sentimentalismo y ensalzar los "avanzados modos de pensar. . ." (Haigh 36). Aparece así una suerte de tensión en el relato entre el carácter racional y emocional de la mujer, y estos rasgos son arbitrariamente exigidos.

4 Respecto a esta vinculación entre la tradición sentimental y la vinculación de lo político con lo erótico y doméstico, se sigue aquí lo propuesto por Pratt (198-205). 
Se trata de un tópico significacional relevante en torno a la forma positiva en que la mujer domina sus pasiones y hace gala de una suerte de intelectualidad y de raciocinio: "Con todo, he conocido varias niñas en Sudamérica, muy adeptas a la literatura inglesa y francesa y que poseían perfectamente ambos idiomas" (Haigh 36). Otro inglés, señalará con evidente etnocentrismo: "Las señoras, en medio de una ingenuidad infantil, son muy inteligentes y tienen, además, otros grandes merecimientos, que exceptuando a Inglaterra, no los alcanzan en otros países" (Caldcleugh 161).

Esta imbricación compleja entre razón y emoción que describe a la mujer en la mirada condescendiente poscolonial, aparece también al relatar el preámbulo de una de las tantas batallas entre realistas y patriotas durante el período de lucha por la independencia. Ahí, se excusa la ausencia de emocionalidad en la despedida que las mujeres chilenas dan a los hombres que van a la guerra. Frente a esta carencia emotiva el viajero señala: "Pero esta no era dureza de corazón; las amables, gentiles y fascinadoras chilenas sentían realmente ese dolor que expresaban sin afectación alguna" (Haigh 67).

El ejercicio objetivador de Haigh le lleva a conocer el verdadero sentir de la mujer que define como una expresión no afectada; emocionales, pero sin emoción. La tensión entre mujeres sin afectación, pero gentiles — y más aún-, fascinadoras, aparece de inmediato profundizada en el esfuerzo del inglés por desmitificar la supuesta liviandad moral de la mujer: “. . .aprovecharé la ocasión para desmentir la impresión. . relativa al estado moral de Santiago, y particularmente en cuanto al bello sexo. Es falso que esta ciudad sea un centro desmoralizado" (Haigh 67).

A pesar de este esfuerzo por desmentir la falta de moral de la mujer Haigh señalará una treintena de páginas después una obra de teatro donde una mujer le es infiel a su marido con un cura (97) y otra obra popular donde una mujer casada es cortejada por un indio: "Entonces llega un indio salvaje que procura obtener las simpatías de la dama, y, mientras la corteja en la forma más civilizada que le es posible, entra el marido, mata al galán; en seguida la mujer se va" (Haigh 98). Más adelante el viajero relatará ya no una historia ficticia de infidelidad sino una verídica donde un sujeto “. . . disponía de algunos indicios para sospechar contra la fidelidad de su esposa que tenía cierta intriga con un oficial. ..” (Haigh 104). En este hecho ya no teatral sino verídico el esposo al descubrir la infidelidad de su esposa mata al amante y la mujer es recluida en un convento.

Otra forma de expresión de la tensión a la que se hace referencia aparece cuando Haigh señala la virtud de la mujer chilena y la alegría que han llevado a sus esposos extranjeros: 
...pienso que el más incontestable argumento a favor de la virtud y carácter femenino de Santiago es que la mayor parte de los extranjeros respetables, franceses e ingleses, después de residir allí algún tiempo, han escogido a la compañera de su vida en el bello sexo de la localidad, sin que en ningún caso se haya oído decir que uno de estos maridos se arrepintiera de esta determinación (68).

La mujer, en esta doble subalternidad (de género y por el hecho de ser criolla), acompaña el hombre; es una especie de guarnición prescindible que solo escolta y realza la contundencia del varón, de ahí que digamos que se trata de una mirada objetivadora donde la mujer aparece como objeto de entretención y servicio. Así, el modelo de mujer servicial aparece en variadas partes del corpus estudiado. Opera en este sentido una forma de lo que Foucault denominó "histerización del cuerpo de la mujer" (127) refiriéndose al proceso mediante el cual el cuerpo femenino es significado exclusivamente como sexualidad, remitiendo así a los deberes conyugales asociados a la crianza de los hijos y el cuidado del hogar.

El citado Caldcleugh (122), por ejemplo, señala mujeres que sirven la comida y preparan el queso. Pero es el relato del viaje a Chile del francés Camille Jacob de Cordemoy donde afloran los mayores rasgos asociados a lo que aquí llamamos la objetivación servicial de la mujer, aunque en su caso esta objetivación queda casi exclusivamente restringida a la mujer indígena mapuche.

Cordemoy señala refiriéndose a la mujer mapuche: "La mujer casada es un modelo de virtud y de resignación. Nada reprobable sobre su conducta, dice un escritor; es la mujer del evangelio. Ella ama mucho sus hijos, los padres también, por cierto" (190). Aparece la mujer idealizada sin ninguna reprobación de conducta; su valor radica en el servicio que presta a sus hijos y marido; "la mujer del evangelio" no tiene voluntad y su realización está en los otros.

Unos años antes el alemán César Maas dirá a propósito de una estadía en casa de un cacique mapuche: "Al poco rato, oímos la voz de Colipí, lleno de furia, rabiando con sus mujeres, por no haber hecho el aseo del patio en debida forma. Acudieron ellas presurosas y dejaron todo como debía quedar" (74). Más adelante el alemán continúa situando a la mujer en posiciones domésticas de servicio como la cocina y el cuidado del huerto, siendo excluidas de las conversaciones y los asuntos considerados varoniles.

Los viajeros europeos lejos de acusar la sumisión de la mujer indígena lo ven como una señal de civilidad y de que estas tribus no eran después de todo tan salvajes. Tanto en Maas como en Cordemoy estas ideas quedan del todo claras, y se trata 
de una "visión pornográfica de los eventos" (Townsend) en cuanto (re)produce una subalternidad donde la mujer no cuestiona al hombre, cuestión en la que hay una suerte de placer latente. El único viajero de los revisados que manifiesta algunas aprehensiones - aunque más implícitas que explícitas - en torno a la restricción de la mujer mapuche a las labores domésticas es el estadounidense Edmond Reuel Smith. Este, después de realizar a lo largo de su relato algunas críticas hacia la poligamia y la forma en que la mujer es tratada como sirviente por los lonkos, termina señalando hacia el final del texto: "Tengo la seguridad de que, si hubiera querido radicarme entre ellos, habría llegado a ser dueño de extensas tierras y de tantas mujeres como mis medios hubiese permitido adquirir" (Reuel 209)

Sin embargo, las mujeres indígenas aparecen en ocasiones posicionadas ya no tan solo como personajes secundarios que acompañan y sirven al hombre sino como protagonistas de las batallas de antaño. Así, y haciendo una referencia directa a La Araucana de Alonso de Ercilla, Cordemoy señala en otra parte de su relato:

Se ha reproducido varias veces el sueño de Lautaro, reposando en los brazos de su querida Guacolda, la noche de su muerte. Sombríos presentimientos lo invaden aquella noche, y su fiel compañera busca consolarle. Las mujeres juegan un gran rol en la época de Ercilla. Aquí aparece la bella Racloma que pasa a nado el río Valdivia, y lleva a los conquistadores las palabras de paz de sus compañeros . . . Las torpederas de la marina chilena llevan los nombres de las heroínas araucanas, poetizadas por el guerrero que combatió contra sus esposos y sus hermanos; Fresia, Guacolda, Jaeneque, Gaule, Quidora, Tegualda, Rucamilla. Todas merecerían aquí un recuerdo. . . (590-1)

Esta descripción tensionada entre la emocionalidad de la mujer mapuche como madre y esposa esmerada y sufriente, y al mismo tiempo asociada a su capacidad de agencia y acción protagónica dirigida a la lucha contra los invasores españoles, configura una descripción compleja de la mujer indígena. Otro viajero, inglés ahora, señala que las mujeres mapuche combatieron junto a sus esposos contra los españoles en tiempos de la colonia y que son por tanto, "Amazonas de Chile" (Schmidtmeyer 341), operando una forma mítica donde aflora simultáneamente una promesa sexual y un peligro sexual. De esta forma, la mujer indígena es simultáneamente sujeto de acción y objeto de representación.

Esta complejidad, configura también el imaginario acerca de la mujer criolla, donde se articulan elementos asociados a la raza y a la clase social para posicionar una suerte de escala machista-colonial, cuya cúspide la ocupan las mujeres blancas 
ricas y que decae pasando por mestizas trabajadoras, indígenas y negras pobres, y todos los posibles cruces que produce la mirada poscolonial. ${ }^{5}$

\section{La mujer como objeto de deseo e intercambio: exotismo y tensiones entre raza y clase}

Indudablemente la mujer aparece en los relatos analizados como objeto de deseo, y es la mujer indígena la que aparece en descripciones más sórdidas y explícitas en cuanto para los viajeros no comparte el mismo grado de civilización -y humanidad- que ellos. Así, los viajeros culparán a las mujeres -indígenas sobretodo- de avivar sus propias pasiones y deseos:

... el mate comienza a circular. Losha, una de las hijas del cacique prepara la yerba. Es una bella criatura Losha; tiene los labios un poco gruesos, pero sus ojos son tan dulces, tan lánguidos. Tiene gestos tan encantadores, tan suaves. Un encanto emana de su persona, se siente que es una mujer, una verdadera mujer, y que ella usa todos sus artificios de seducción de los que puede ser capaz una India (de la Vaulx 222). ${ }^{6}$

La mujer es la culpable de la seducción del hombre; seducción que probablemente solo haya sido producto de la imaginación del viajero. Así, cuando además de ser mujer, se es indígena, se dan las condiciones para un trato aún más peyorativo y de ánimo de posesión: el europeo es superior al indígena, superioridad que aumenta cuando el indígena es mujer: "La alteridad del indígena se adjuntará a la de la mujer para estructurar una doble heterosexualidad que articulará el género y la "raza" para avivar mejor el deseo del hombre blanco" (Staszack 139).

La mujer desciende de Eva y es por tanto la culpable de todos los males del hombre, así lo señala el geólogo sueco Otto Nordenskjöld a propósito de su viaje en

5 En este sentido, no se desconocen aquí las diferencias de raza y clase que operan en la mirada objetivadora de género en los relatos de viajeros que se estudian. Al respecto, parece pertinente incluir aquí aquellos elementos que son relativamente comunes (la objetivación servicial y la sexual) tanto de mujeres chilenas criollas, como de mujeres mapuches indígenas. La necesidad de considerar la interseccionalidad es sin duda relevante, aún cuando este concepto ha sido utilizado para el análisis de las representaciones de mujeres negras (Carastathis 1), o en las dinámicas de racismo en la académia norteamericana (Crenshaw et al. 11). Con todo las definiciones en torno a la interseccionalidad ofrece lineamientos teóricos útiles para la articulación de las categorías de raza y clase que se hace necesario considerar como parte de futuras investigaciones.

6 El viaje del Conde Henry de la Vaulx a la Patagonia chileno-argentina se realiza en 1896 y el relato es publicado en la revista francesa Le Tour du Monde en 1900. 
la Patagonia chilena: "Todas las mujeres portan alrededor del cuello y de los brazos collares. . Inútil es señalar que en la Tierra del Fuego como en todas partes, los objetos de adorno ejercen el más grande atractivo para las hijas de Eva. . ." (Nordenskjöld 34). ${ }^{7}$ Esta referencia a la coquetería y la vanidad por el uso de joyas aparece referida en otros viajeros: "La dueña de casa [una mapuche], para honrar a sus visitas, o tal vez por una perdonable vanidad femenina, apareció el día siguiente a nuestra llegada, con la cara recién pintada y luciendo todas sus joyas" (Reuel 182).

Por su parte, el alemán Aquinas Reid asocia la moda y la vanidad a la negatividad propia de toda mujer: "Aquí, como en todo el mundo, reina también la moda, y en verdad no hay gran diferencia entre las sartas de chaquira que envuelve el cuello de una ignorante indígena de Chile, y el collar de oro de alguna farsante imperial" (66).

Aparece así la tensión entre etnicidad y género a la que se ha hecho referencia; en ocasiones son las mujeres indígenas las más denostadas, en otras, la distinción racial no aplica y da igual si la mujer es indígena o una farsante imperial; todas son súbditas de sus deseos y pasiones, en este caso, la moda, coquetería y vanidad.

La tensión en los términos recién expuestos se da también respecto a la categoría de clase, al respecto el inglés Nelson Boyd señala sobre las mujeres criollas, sin importar su condición de clase: “. . .desde la más fina esposa de un "Don” hasta la más baja hija de un peón se deleitan en usar vestidos con cola ridículamente larga. . . el algodón pronto se ensucia con el barro. . . esto agrega mucho a su desarreglada y sucia apariencia” (Boyd 41).

Así, y volviendo a la mujer como objeto de deseo, no son solo las mujeres indígenas quienes son reducidas en este sentido. De hecho, la mirada imperial hacia las mujeres criollas opera también a través de una forma de exotización donde se mira lo criollo como una suerte de semi-civilización, no tan bárbaro como lo indígena, pero sí una suerte de copia forzada e incompleta de los parámetros europeos. Es por eso que los territorios criollos son parte de los territorios del confín imperial (Sandoval 91):

La regularidad y dulzura de la fisonomía son cosas comunes entre las chilenas, pero la elegancia en el andar, la gracia del movimiento, la delicadeza de las formas, nos parecen el privilegio de una minoría muy reducida hoy día, minoría a la cual una sangre libre de toda mezcla conserva sin duda su perfección

7 Viaje realizado en 1895-1896 a la Patagonia chileno-argentina y publicado en la revista de viajes francesa Le Tour du Monde en 1902. 
original: nos referimos a la raza de los conquistadores, de las hijas de la vieja España (Radiguet 226).

En otra parte de su relato las criollas-mestizas adquieren en el imaginario del francés Radiguet la figura mítica de las Amazonas. De esta forma se exotiza y erotiza a las mujeres criollas, poniéndolas en un rango similar a la de las indígenas que vimos en los textos anteriores, y a las que el viajero describe absorto por las festividades veraniegas del centro de Chile: "Alegres cabalgatas atraviesan las calles, amazonas sin sombrero, tules y cabelleras al viento, destellos en todos los ojos, sonrisa en todos los labios; . . durante las semanas consagradas por entero a la fiesta y a las distracciones elegantes, se comprende el atractivo que siempre Valparaíso ha tenido para los viajeros y para los marinos de todas las naciones" (Radiguet 235).

Así, este viajero pone en entredicho la escala racial que sugiere que mujeres indígenas son inferiores a las mujeres criollas. Para Radiguet la mujer es objeto de deseo independiente de su condición racial y las criollas quedan también reducidas a "amazonas sin sombrero"; lo semi-civilizado (el mundo criollo) queda unido a lo incivilizado o bárbaro (el mundo indígena de las amazonas, en este caso imaginario). Sin embargo, esta dimensión es compleja puesto que, como se ha visto, en otras partes de su relato Radiguet posiciona claramente una distinción valorativa entre la "sangre libre de toda mezcla" (226) y los mestizajes entre criollos e indígenas.

Quizás la complejidad en la diferencia propuesta se relaciona con que la distinción señalada por Radiguet no es tan solo una distinción racial, sino también una distinción de clase. Radiguet se refiere además no a amazonas, sino a otro referente mítico-imaginario que reduce a la mujer a una condición semi-humana, con una mezcla de animalidad peligrosa para el hombre, la sirena:

Respecto a los marineros, ¿será necesario decir lo que los atrae en las quebradas? Por donde quiera que haya una puerta o ventana, puede notarse, sentadas sobre el umbral de las unas o inclinadas sobre las otras, algunas niñas de cara fresca y sonriente. . . Un guiñeo (sic) de la muchacha y un saludo de la vieja, acompañado de esta expresión hospitalaria: "La casa a disposición de usted", atraen al marinero a un antro más peligroso que el de las sirenas; los roles de tripulación constatan este hecho, agregando al nombre de la víctima por todo comentario estas tres palabras: desertado en Valparaíso (Radiguet 219).

Es en las quebradas, espacio privilegiado de las clases bajas de la época -y para Radiguet, el lugar donde viven las sirenas_-, donde se articula una dimensión 
de clase asociada a la feminidad, pues en otra oportunidad, y a propósito de una visita a la casa de uno de los "notables" donde fue recibido para comer y bailar, el francés señala: "Cuando entramos al salón, el dueño de la casa, . . .pronunció con gravedad castellana, la fórmula corriente: La casa está a disposición de ustedes, caballeros, fórmula que en esta ocasión tenía una acepción enteramente diferente a la que tiene en las quebradas. .." (Radiguet 228).

Se marca entonces una diferencia de clase; mientras en las casas de las quebradas la fórmula se asocia a la prostitución, en las casas de los notables la frase funciona como parte de las normas de hospitalidad. Sin embargo, también en estos espacios de nobleza la mujer actúa también erotizada al igual que las "sirenas": en los salones nobles: “. . . las chilenas son dos veces mujeres cuando se trata de penetrar un misterio de amor" (Radiguet 230). Aparece entonces la dimensión del ego fálico a la que nos hemos referido y el viajero al igual que su compatriota De la Vaulx, ve coquetería y seducción en todo lo que rodea las festividades a las que asiste, incluso cuando toman mate: ". . .le presenta el vaso del mate a medio llenar, con la bombilla aun húmeda por el contacto de sus rosados labios” (Radiguet 231).

La tensión de clase y género parece bascular cuando el viajero relata con lujo de detalle, en extensas dos páginas, el baile de la zamacueca que ve en uno de los salones nobles y que, al parecer, estaría en la época en desuso por considerarse reñido con las buenas costumbres: “ “. . se comienza a repudiar esos dramas coreográficos en que el juego de la fisonomía y la movilidad del gesto suplen tan maravillosamente a la palabra. Así la zamacueca, danza graciosa y coqueta, se ha visto relegada a las clases bajas de la sociedad. .." (Radiguet 233).

Sin embargo, el mismo viajero dirá más adelante que frente a este síntoma de repudio de la zamacueca, las fiestas de verano donde las mujeres santiaguinas van a Valparaíso hacen resurgir este baile, y nuevamente la categoría social de clase entra en tensión: “. . .el atractivo del placer prevalece sobre los prejuicios absurdos, y la zamacueca desterrada, reaparece tímidamente, por último triunfante con la corona en la frente y saludada por numerosos bravos" (Radiguet 234).

Así, la diferencia de clase es puesta en cuestionamiento y aparece, en la mirada imperial del viajero, el latente deseo de baile coqueto en la nobleza chilena:

La niña tiene a menudo cierta afectación de desdén, mientras el caballero continúa sus pasos hasta encontrarse de frente con la bella desdeñadora, mos-

8 Lo mismo es señalado por Reuel Smith: "La zamacueca ha sido muy difamada por los extranjeros que la han visto solo en los puertos y en las localidades de carácter cuestionable. . . En la mejor sociedad de la capital y de los puertos se ha desterrado la zamacueca, por el hecho de ser plebeya. .." (138). 
trando durante ese juego una constancia heroica con la cual concluye por agradarla, pues ella, poco a poco, se humaniza y se acerca a él; pero, llamando luego en su ayuda toda la fuerza de su voluntad, se aleja nuevamente, hace aún otras piruetas y trata de evadirse del encanto que la desvanece.

¡Vanos esfuerzos! La pasión la arrastra; un último esfuerzo la conduce a su compañero, como el fierro al imán, y deja caer su pañuelo. Cuando baila la zamacueca, la mujer del pueblo lo hace con un ardor sin igual (Radiguet 234).

En este baile, como se ve en la cita expuesta, el seductor es el hombre y ya no la "sirena" de las quebradas o la indígena "hija de Eva", tampoco la criolla "amazona". Al contrario, la mujer se resiste - pero con desdén-, con muestras de deshumanización por ausencia de pasión. Finalmente, la mujer se humaniza por la constancia heroica del hombre que la rescata de su frialdad otorgándole la emoción de la que carece: la capacidad de sentir. Se aprecia cómo la mirada erótica desplegada por el viajero - o el ego fálico, si se prefiere- tensiona las dinámicas de clase al posicionar este baile, cuestionado moralmente por las clases acomodadas, precisamente en el centro de los salones nobles. Sin embargo, la distinción de clase se hace también presente cuando el viajero señala: "Cuando baila la zamacueca, la mujer del pueblo lo hace con un ardor sin igual". La mujer de clase baja aparece ligada a un componente erótico sobre exaltado desde la mirada del viajero.

Por otra parte, se aprecia en términos de la objetivación sexual que aquí se refiere, que lo que interesa a viajeros como Radiguet en su descripción de las mujeres es la juventud, la pasión y la alegría; no interesan las mujeres viejas. Cuales mercancías-objetos las mujeres que tienen valor son las jóvenes saludables y bellas. Así, en torno a una excursión a los conventos de Santiago Samuel Haigh se pregunta respecto a ". . la utilidad de estos institutos, mezcladas con cierta tristeza por tanta juventud, inocencia y amor, condenados a "perderse en la sombría soledad de un convento", en vez de permanecer en el mundo para ser la gracia y adorno de la sociedad" (Haigh 98).

Nuevamente, la importancia de la mujer no está dada por el valor que en sí misma posee, sino en cuanto objeto que "adorna" y da "gracia" a los ojos del varón. Esto se aprecia claramente cuando Haigh llega al convento y señala: 
Mientras tales cosas hilvanaba yo en la mente, entré a la iglesia y me aproximé al enrejado, donde mi imaginación vióse de súbito contenida y gradualmente menoscabada mi piedad por el destino de esas mujeres; había allí unas cuarenta fisonomías, ipero qué fisonomías! ¡Parecían piñas disecadas! La mayoría eran viejas y entre todas no vi una sola por la cual yo me hubiera resuelto a escalar una muralla o quebrar un cerrojo (99).

Las "piñas disecadas" no tienen la frescura, adorno, ni la gracia de las jóvenes, y por lo tanto, todas las expresiones compasivas respecto a la inoperancia de recintos como los conventos quedan de lado porque las mujeres que están ahí no responden al gusto del viajero; son viejas y sin lindas fisonomías. La enfermedad y la vejez le quitan belleza a la mujer. De manera similar Caldcleugh señala al llegar a una posada: ". . .la mujer de la casa y una de sus hijas sufrían un tumor o coto en la garganta; la otra era muy bonita” (Caldcleugh 122).

Como se ve, incluso un viajero más bien naturalista — geólogo, en rigor-como Alexander Caldcleugh, que no deja de mirar el suelo en búsqueda de piedras y minerales, reproduce también el ethos poscolonial asociado a la estetización y erotización de las mujeres subalternas que encuentra en el viaje. La idea de histerización de la mujer (Foucault 127) es otra vez relevante para entender el cuerpo femenino saturado de sexualidad, tal como se revisó en la objetivación servicial de la mujer:

Las niñas de Santiago poseen gran encanto personal, además de un natural muy dulce, y son un poderoso incentivo para volver al país, pero ciertamente su carácter queda por encima de toda duda. El apuntar que hay un poquito de coquetería y el notar que con frecuencia, al componerse el chalón, con el cual cubren los otros atavíos, pueda uno recrearse, contemplando siluetas muy atrayentes, no significa, ni con mucho, echar sombras sobre la delicadeza de su carácter, punto del cual se enorgullecen (Caldcleugh 161).

El "chalón" o manto que cita Caldcleugh, y en torno al que construye esta mirada colonial que exotiza y pone de manifiesto las "siluetas atrayentes" y la "coquetería", funciona para el viajero como una prenda que muestra ocultando, y que en este sentido opera de la misma forma que el velo oriental en las fantasías eróticas también (pos)coloniales de los parajes africanos y asiáticos. Al respecto, el teórico francés Jean Francois Staszack señala, a propósito de la fijación de los europeos con los velos presentes en las danzas orientales: 
En occidente y en particular desde el siglo de las luces (apelación reveladora en la materia), el saber es concebido como una observación capaz de ver la verdad escondida detrás de las apariencias ...El proyecto científico moderno se inscribe dentro de una epistemología de quitar el velo y de voyerismo, mezclando los deseos de ver, de saber y de poder. Desde esta perspectiva se comprende porque el velo juega un rol importante dentro de los fantasmas orientalistas, y como el striptease, particularmente si es exótico, se inscribe dentro de una empresa de objetivación y dominación del cuerpo del otro. . . (Staszack 140)

Sin embargo, el manto o chalón no solo sirve como elemento exotizador desde la mirada colonial-fálica europea, sino que también como un elemento homogenizador que, desde la perspectiva tanto de la mujer como del hombre, elimina las distinciones de raza al dejar solamente al descubierto parte de los ojos. Al respecto, el propio Caldcleugh cuenta en tono de jocosa anécdota que durante su estadía en Lima conoció un inglés que, al sentirse atraído por el físico de una mujer, la siguió para saber dónde vivía: "La siguió por varias calles, y cuando ella entró a su casa, se bajó el manto con gran asombro del inglés que vio a una negra" (Caldcleugh 199). El manto funciona como eliminador de las distinciones de clase y raza, pero una vez que la mirada imperial se percata de la diferencia no duda en ponerla a la vista y hacer mofa de ella. Opera en este sentido una suerte de dislocación de clase donde el viaje permite poner en relieve estos elementos y da lugar a "disfrazar" las clases sociales y ponerlas en contacto (Walchester 41).

A partir de lo revisado se considera que en los viajeros decimonónicos se encuentran atisbos de lo que hoy se conoce como turismo sexual. Parte de la práctica del viaje responde a esta dimensión picaresca y con tintes eróticos que queda refrendada en los relatos del viaje realizado.

Los viajeros al parecer conversaban estos asuntos entre sí y seguramente alardeaban de sus conquistas amorosas durante el viaje y su estadía en los territorios del confín. Al respecto, tenemos el caso del alemán Carl Alexander Simon que viajó a Valdivia y al sur de Chile, teniendo una estadía en Chiloé. ${ }^{9}$ El diario de Simon no ha sido traducido al español y, al parecer, la única copia se envió a su esposa en Alemania — quien se hacía cargo de nueve hijos— posterior a la muerte de Simon.

9 La historia de Simon, particularmente su estadía en Chiloé ha sido detalladamente documentada por Van Meurs (49), con acento en la producción iconográfica del alemán en la mentada isla. 
Rodolfo Philliphi —otro alemán— señala en una carta a Luis Montt respecto al diario de Simon: ${ }^{10}$

En este diario de vida él le reprochaba a mi hermano no tener corazón, porque no le contaba sus amores. Es que mi hermano tenía en este tema simplemente opiniones muy distintas a las del reformador del mundo Simon, quien cuenta [en el diario] con gran holgura cómo sedujo a una joven chilota, para decirlo brevemente, y cómo ella, la tarde misma antes de su matrimonio con un chilote le habría concedido, ante su insistencia, un encuentro cerca de un pozo y le habría "permitido todo". Era este el mismo hombre que en 1830 veneraba la imagen de su amada Amelie? Me he reservado esta parte de su diario de vida, de manera que no llegara a manos de su viuda. (R.A. Philippi, citado por Van Meurs 50).

Los viajeros, según se aprecia en el texto, cubrían sus infidelidades unos a otros en el marco de la permisividad que se daba en los territorios que visitaban. Otros tantos, al ser solteros, hacían gala en sus diarios de sus conquistas amorosas, o simplemente de sus intentos por hacerse de una esposa. Ejemplo de esto es el del belga Gustave Verniory quien intentó sin éxito cambiar un cuchillo que era deseado por un mapuche por alguna joven mujer mapuche:

Está loco por el puñal, me ofrece en cambio un cordero, después dos, enseguida tres, a los cuales agrega todavía una vaca. Rehúso noblemente. No cedería mi puñal sino por una "vita piri" (joven) que no haya visto más de quince cosechas. Esto turba fuertemente a mi indio. El no tiene "ñaña" (hermana), pero buscará. . . dejaremos para más tarde la conclusión del negocio (Verniory 429-30).

También Henry de la Vaulx —el mismo que antes acusó a las indígenas de seductoras — se acercó a una mujer anciana para tratar de desposar a su hija: ${ }^{11}$

10 Se considera relevante este ejemplo, sin ser un relato de viaje sino una carta, referida a su vez a un diario de vida, porque da cuenta de cómo el ego fálico va más allá del relato de viajes mismo y opera de manera selectiva en torno a lo que se puede y no decir en el texto: "Al poner la aventura por impreso, los escritores viajeros consideran detenidamente a los lectores que podrían verse impactados por anécdotas riesgosas y a aquellos que las disfrutarían" (Aldrich 520). Por otra parte, las cartas mismas escritas en el viaje constituyen parte del viaje y su relato. Sobre las formas que toma el relato de viajes ya sea como crónica, diario, carta, etc. Ver Kinsley (408).

11 Desde la lectura propuesta, hay aquí una forma de explotación sexual poscolonial sin existir, lo que Pratt denomina "una versión sentimental de la anticonquista" (188), ya que no hay romanticismo en los casos de Verniory y Cordemoy o historias de amor transracial como las expuestas por Pratt (179-98). 
Le pregunto entonces a la vieja si quiere darme a su hija María como mujer. Y agrego: "Te daré dos yeguas a cambio". Pero la india dice que no. "Te daré tres yeguas". No, responde la vieja. "Te daré cuatro". Entonces ella piensa. En sus ojos hay un brillo codicioso, después, de repente me toma el brazo. "Cuatro yeguas dices tú, eso es caro, muy caro. ¿Por qué no me desposas a mí? Soy más barata que María y aún soy muchacha" (que quiere decir mujer joven y ardiente). Intenta la vieja decir en un mal español. Yo me rio a carcajadas. . nos vamos de la carpa, ante una gran desilusión de la India, que cree que ha perdido un buen negocio por sus proposiciones extrañas (de la Vaulx 242).

El intercambio de la mujer como objeto material aparece avalado por el hecho de que los europeos veían su presencia en el territorio como justificada para obtener riquezas y que, en última instancia, todo les pertenecía. Se trata de lo que se ha denominado "discurso de la anti-conquista" (Pratt 35), en cuanto se trata de afirmar de manera simultánea la inocencia y la superioridad europea. Un ejemplo de esto aparece más claramente en la escena que relata el Alemán Paul Treuttler al hospedarse en casa del mapuche Railef:

Como la casa no era grande, mi anfitrión había mandado preparar mi lecho - como demostración de especial confianza- en el mismo apartamiento en que dormía con su mujer y sus hijas, y como ese recinto era muy estrecho, tuve que acostarme inmediatamente al lado de las hermosas muchachas. Pero ruego al lector no vea algo inmoral en ello, pues es conocida la absoluta inocencia de esta raza, que castiga con la pena capital el adulterio y la seducción (Treutler 387).

Se da en el caso de Treuttler el "discurso de la anti-conquista" en cuanto el alemán se preocupa de quitarle la potencialidad erótica a la escena que relata y se nos presenta en una suerte de androginia e impotencia. Aunque, claro está, el viajero toma en consideración lo exótico que resultará para sus lectores europeos el compartir lecho como cuestión inocente, y despertará quizás la duda respecto al comportamiento de Treuttler. Así, y contradictoriamente, Treuttler erotiza la escena al pretender deserotizarla, y se pone de manifiesto el discurso de la anticonquista: ". . .encontrar una manera de tomar posesión sin dominación y sin violencia” (Pratt 117). Así, el viajero hace gala de una interesante tensión entre lo público y lo privado, puesto que en su privilegio de viajero al acceder a lo que las pautas de su cultura señalan como espacio privado — el lecho donde duermen mujeres que no son la propia esposa-, Treuttler tiene la oportunidad de hacer público y compartir estas 
pautas culturales tan disímiles a las propias, configurando así el discurso exotista que ya se ha referido.

Tanto el territorio, la tierra, como sus habitantes aparecen exotizadas y caracterizadas con epítetos que aluden a la conquista no tan solo material del espacio sino a la conquista simbólica visualizada en la erotización y objetivación sexual que aquí se ha expuesto. Al respecto, Verniory escribe acerca de sus sentimientos al entrar la selva: "Es la primera vez que yo penetro en una selva enteramente virgen. ¡Qué esplendor!” (113). La conquista del territorio aparece en términos que no son directamente coloniales sino como la conquista de lo antes exótico y natural en lógica poscolonial por la materialidad del mundo social civilizado donde los viajeros europeos son la supuesta 'luz del progreso'. El ingeniero Verniory penetra la selva virgen en pos de la construcción de las líneas férreas del sur de Chile, de la misma forma en que pensó desposar a una joven mapuche a la que quiso cambiar por un cuchillo. La estetización que aplica el belga para referirse al paisaje de la selva, se acerca mucho a la idea de erotización a través de la seducción. La retórica propuesta reduce todo el territorio y sus habitantes al cuerpo femenino que debe ser penetrado. Al respecto Spurr señala sobre el discurso poscolonial: "El gesto retórico en el que se alegoriza un pueblo entero mediante el cuerpo femenino tiene sus orígenes en las fantasías de seducción, es decir, en las escenas imaginarias que representan la realización del deseo sexual" (272).

\section{A modo de conclusión: límites y posibilidades de la vinculación entre relato de viajes y los estudios de género}

El principal límite en el análisis propuesto se refiere a que se reproduce aquí el discurso preponderante del s.XIX que posiciona a la mujer como objeto de violencia y exclusión en lugar de dar visibilidad a las escrituras femeninas. En este sentido, queda pendiente un ejercicio de "contra-tradición”, según lo propuesto por Alvarado, donde se pueda analizar a la mujer como sujeto de deseo en su propia narrativa de viajes con su propia voz y tensiones, lo que permitiría salir del "falogocentrismo" (42) decimonónico donde los hombres ejercen el oficio de las letras.

En este sentido los textos deben ser leídos como parte del ánimo objetivador y la expresión de los deseos de los viajeros más que como la realidad misma. Opera en este sentido una forma de mímesis que es quizás uno de los aspectos más críticos del relato de viajes. Así, y si decimos que el viajero da cuenta más de su imaginario y el de su partida que el de su destino, y que hay una relación estrecha entre esto y los proyectos de las élites locales en el s. XIX (Pinto 168), entonces es preciso poner un manto de duda sobre las descripciones vertidas en torno a lo 
cotidiano, porque es precisamente ese cotidiano siempre disperso, heterogéneo y fragmentado el que las élites locales pretendían unificar y homogenizar en pos de los modos de vida europeos, supuestamente civilizados.

De este modo, hay que cuestionar sobretodo los espacios discursivos en que los viajeros ponen acento en las desviaciones y vicios del cotidiano de los sujetos sobre los que escriben —en este caso las mujeres_- puesto que hay en esto un esfuerzo normalizador por imponer sus visiones de mundo civilizadas y el orden socio-económico de una serie de dispositivos de control como lo son: empresas productivo-extractivas, escuelas, cárceles, obras arquitectónicas, conventos, etc. que se constituían en una doble dinámica. La primera dinámica responde a un fin significacional y representacional, donde estos dispositivos venían a reemplazar la barbarie por la civilización. La otra dinámica es más bien material y de las prácticas, donde la implementación de estos dispositivos suponía sendos réditos económicos para las empresas de bienes y servicios, arquitectónicas, la contratación de personal calificado que era casi exclusivamente europeo, etc.

De manera que si bien los relatos de viaje representan un aporte para la (re) construcción de las dinámicas sociales en general, y de género en particular, con el consiguiente hincapié que hacen en las tradiciones, lo cotidiano y lo costumbrista, no deja de ser cierto que esas descripciones pueden estar mediadas por la necesidad de implementación de dispositivos de control. Intentar una interpretación desde los sujetos subalternizados aparece entonces como una necesidad imperiosa. Es decir, pensar las dinámicas descritas por los viajeros no desde su locus paternalista-civilizatorio-patriarcal, sino avizorar otros espacios de significación, donde lo que para los viajeros era algo negativo y vicioso para los sujetos descritos puede haber sido parte de un virtuosismo que les permitía desenvolverse socialmente.

En línea con lo anterior, las posibilidades para abordar la dimensión de género con una mirada que considere la voz de las mujeres como sujeto del viaje aflora como una de las extensiones a abordar por parte de la investigación aquí propuesta. De hecho, en el marco de la pesquisa de fuentes que se ha realizado en el proyecto que da lugar a esta investigación, se han encontrado dos relatos de viaje poco referenciados y donde se escribe sobre Chile; el de la austriaca Ida Pfeiffer ( $A$ woman's Journey Round the World) y el de la inglesa May Crommelin (Over the Andes).12 Si se considerara estos textos junto a otros más conocidos en Chile (María Graham y Florence Dixie, por ejemplo) se daría lugar a posibilidades comparativas más que interesantes. De todas formas, los relatos de viajeras son menos numerosos

12 Se tiene referencia de edición en español del primero (editorial Barrabés, Huesca, 2006), mas no del segundo. 
que aquellos escritos por hombres en cuanto en todos los viajes decimonónicos y de principios del siglo XX prima la idea de la aventura y la exploración, donde en aquel tiempo los hombres tenían una mayor posibilidad de desenvolvimiento en el espacio público mediante este "mito del explorador heroico" (Basnet 225).

De todas formas, y a pesar de las limitaciones señaladas, se considera relevante el análisis propuesto, porque se relaciona con la posibilidad de entender y complejizar la forma en que se expresaron las masculinidades europeas en América Latina en tiempos del colonialismo poscolonial, donde se encuentran ya trabajos como el de Peluffo \& Sánchez (9-11). Es preciso entonces evitar el riesgo esencialista que llevaría a pensar a todos los hombres como igualmente caracterizados por el ego fálico que hasta aquí hemos descrito.

Así, resulta evidente en el análisis propuesto que la mirada del ego fálico no es idéntica en viajeros como Alejandro Caldcleugh, cuyo viaje en Chile está más asociado a la prospección minera que a otra cosa, que en un viajero con el perfil de Max Radiguet, cuyo relato se centra en la bohemia porteña de Valparaíso y que, como se ha visto, ve coquetería y pasión en todos lados.

Del mismo modo, no pueden ser considerados de igual forma los encuentros de Henry de La Vaulx y de Gustave Verniory con mujeres mapuche y sus intentos por desposarlas. Mientras que en estos el ánimo machista se hace más evidente al mezclarse con el prejuicio étnico-racial y llega al punto de intentar la compra de mujeres, en otros viajeros como César Mass o Paul Treuttler no se observa tal nivel de descaro. En este sentido se optó en este trabajo por considerar la representación en los relatos tanto de la mujer criolla (chilena) como de la mujer mapuche aludiendo de manera muy clara a si los europeos se acercaban a la una o a la otra a fin de no caer en homogenizaciones impertinentes. Al respecto, el campo de estudio de los relatos de viaje y los estudios de género se ha visto complejizado en años recientes por la incorporación de las nociones de raza, clase y teorías del espacio (Bird 101), cuestión que aparece también como posibilidad de explorar en detalle a futuro. 


\section{Obras citadas}

Aldrich, Robert. "Gender and Travel Writing". The Cambridge History of Travel Writing. Eds. Nandini Dans, Tim Youngs. Cambridge: Cambridge University Press, 2019: 520-534.

Alvarado, Marina. "Contra-tradición: prácticas críticas y desestabilizadoras de escritoras chilenas de principios del siglo XX”. Ogigia 5 (2008): 41-51.

Basnet, Susan. "Travel writing and gender". The Cambridge Companion to Travel Writin. Eds. Peter Hulme, Tim Youngs, Cambridge: Cambridge University Press. 2002. 225-241.

Bird, Dúnlaith. "Gender". Keywords for travel writing studies. Eds. Charles Forsdick, Zoë Kinsley, Kathryn Walchester. London: Anthem, 2019: 99-101.

Boyd, Nelson. Chili: sketches of Chili and the chilians during the war 1879-1880. Londres: Woodfall and Kinder, 1881. [Trad. Prop.]

Caldcleugh, Alexander. "Viaje a Chile en 1819, 20, 21". Viajeros en Chile. 1817-1847. s.e. Santiago de Chile: Ed. Del Pacífico, 1955.

Carastathis Anna. Intersectionality: origins, contestations, horizons. Nebraska: University of Nebraska Press, 2016.

Chrisman, Laura. "Postcolonial Studies". New dictionary of the history of ideas. 2005.

Cooper, Frederick. Colonialism in Question: Theory, Knowledge, History. Los Angeles: University of California Press, 2005.

Cordemoy, Camille Jacob. "Au Chili [I]". Le Tour du Monde, nouveau journal des voyages [Paris, Francia]. Nouvelle série, 2e année : 577-624, 1896. [Trad. Prop.]

Cordemoy, Camille Jacob. "Au Chili [II]". Le Tour du Monde, nouveau journal des voyages [Paris, Francia]. Nouvelle série, 4e année : 181-216, 1898. [Trad. Prop.]

Creensahw, Kimberlé; Harris, Luke; HoSang, Daniel; Lipsitz, George, eds. Seeing race again: countering colorblindness across the disciplines. Oakland: University of California Press, 2019.

De la Vaulx, Henry. "Voyage en Patagonie". Le Tour du Monde, nouveau journal des voyages [Paris, Francia]. Nouvelle série, Ge année : 193-264, 1900. [Trad. Prop.] 
Dussel, Enrique. 1492. El encubrimiento del otro: hacia el origen del mito de la modernidad. La Paz: Plural editores, 1994.

Feliú, Guillermo. Viajes relativos a Chile (tomo I y II). Santiago de Chile: Fondo Histórico y Bibliográfico José Toribio Medina, 1962.

Figueroa, Virgilio. Diccionario histórico, biográfico y bibliográfico de Chile. Santiago: Ed. Balcells, 1928.

Foucault, Michel. Historia de la sexualidad 1. La voluntad de Saber. 31 ed. México: Siglo XXI, 2007.

Gallegos, Eduardo; Otazo, Jaime. "Los relatos de viajes y la conformación de los medios de comunicación modernos en torno las categorías de información y espectáculo”. Revista Latina de Comunicación Social. No74 (2019): 840-856.

Haigh, Samuel. "Viaje a Chile en la época de la independencia". Viajeros en Chile. 1817-1847. s.e. Santiago de Chile: Ed. Del Pacífico, 1955.

Junqueira, Mary Anne. "Elementos para uma discussão metodológica dos relatos de viagem como fonte para o historiador". Cadernos de Seminários de Pesquisa (vol. II). Eds. Mary Anne Junqueira \& Stella Maris Scatena Franco. Sao Paulo: USPFFLCJ-Editora Humanitas, 2011: 44-61.

Kinsley, Zöe. “Travelogues, Diaries, Letters". The Cambridge History of Travel Writing. Eds. Nandini Dans, Tim Youngs. Cambridge: Cambridge University Press, 2019: 408-422.

Lindsay, Claire. "Travel Writing and Postcolonial Studies". The Routledge Companion to Travel Writing. Ed. Carl Thompson. New York: Routledge, 2016: 25-34.

Mass, César. "Viaje a través de las provincias australes de la República de Chile desde enero hasta junio de 1847”. Travesías por la Araucanía: Relatos de viajeros de mediados del siglo XIX. Comp. Italo Salgado. Temuco: Ed. Universidad Católica de Temuco, 2016: 29-94.

Nordenskjoeld, Otto. "La terre du feu". Le Tour du Monde, nouveau journal des voyages [Paris, Francia]. Nouvelle série, 8e année: 13-60, 1902. [Trad. Prop.]

O'Halloran T.P. A Bibliography of South America. Buenos Aires: Librerias MacKern, 1912.

Peluffo, Anna; Sánchez, Ignacio, eds. Entre hombres: Masculinidades del siglo XIX en América Latina. Madrid: Iberoamericana/Vervuert, 2010. 
Pinto, Jorge. "Proyectos de la elite chilena del siglo XIX (I)". Revista Alpha, No 26 (Julio 2008): 167-189.

Pratt, Mary Louise. Ojos imperiales: Literatura de Viajes y Transculturación. México D.F: Fondo de Cultura Económica, 2010.

Rabasa, José. "Poscolonialismo". Diccionario de Estudios Culturales Latinoamericanos. 2009.

Radiguet, Max. "Valparaíso y la sociedad chilena en 1847”. Viajeros en Chile. 18171847. s.e. Santiago de Chile: Ed. Del Pacífico, 1955.

Reid, Aquinas. De Valparaíso al Lago Llanquibue. Diario del viaje efectuado por el Doctor Aquinas Reid en 1847. Santiado de Chile: Imprenta Universitaria, 1920.

Reuel,Edmond."Losaraucanos. Notas sobreunagiraefectuada entrelastribusindígenas de Chile Meridional". Travesías por la Araucanía: Relatos de viajeros de mediados del siglo XIX. Comp. Italo Salgado. Temuco: Ed. Universidad Católica de Temuco, 2016: 123-242.

Sandoval, Oriette. "La mirada imperial y su desplazamiento hacia los espacios de confín: el caso de la narrativa de viaje de Florence Dixie a Patagonia". Taller de Letras Nº 63 (2018): 91-105.

Scatena, Stella. "Relatos de viagem: reflexões sobre seu uso como fonte documental". Cadernos de Seminários de Pesquisa (vol. II). Eds. Mary Anne Junqueira \& Stella Maris Scatena Franco. Sao Paulo: USP-FFLCJ-Editora Humanitas, 2011: 62-86.

Schmidtmeyer, Peter. Travels into Chile over the Andes, in the years 1820 and 1821. Londres: McDoall, 1824.

Scott, David. "Sex/sexuality". Keywords for travel writing studies. Eds. Charles Forsdick, Zoë Kinsley, Kathryn Walchester. London: Anthem, 2019: 223-225.

Spivak, Gayatri. "Postcolonial Theory and Literature". New dictionary of the history of ideas, 2005.

Spurr, David. La retórica del imperio: El dicurso colonial en periodismo, escritura de viajes y administración imperial. Santiago: Ed. Universidad Alberto Hurtado, 2013.

Staszak, Jean François. “Danse exotique, danse érotique. Perspectives géographiques sur la mise en scène du corps de l'Autre (XVIIIe-XIXe siècles)". Annales de Géographie No660- 661, Año 117 (Marzo-Junio 2008): 129-158. 
"Amazonas sin sombrero": El ego fálico (pos)colonial y la objetivación de la mujer...

Eduardo Gallegos

Thompson, Carl. Ed. The Routledge Companion to Travel Writing. New York: Routledge, 2016.

Townsend, Camilla. "Burying the White Gods: New Perspectives on the Conquest of Mexico". American Historical Review 108:3 (June 2003): 659-687.

Treutler, Paul. Andanzas de un alemán en Chile 1851-1863. Santiago de Chile: Ed. Del Pacífico, 1958.

Van Meurs, Marijke. Carl Alexander Simón en Chiloé, 1852. Ancud: Ediciones Museo Regional de Ancud, 2016.

Verniory, Gustave. Diez años en la Araucania 1889-1899. 2a edición. Santiago: Ed. Pehuén, 2001.

Walchester, Kathryn. "Class". Keywords for travel writing studies. Eds. Charles Forsdick, Zoë Kinsley, Kathryn Walchester. London: Anthem, 2019: 40-42. 